\title{
A study on the feasibility of distributing iron supplements in school
}

\author{
Myrtle Perera' \\ The Ceylon Journal of Medical Science 1999; 42: 87-93
}

\section{Introduction}

A recent national survey of nutrition status has highlighted the prevalence of anaemia among school children. More than one-half $(58 \%)$ of the children between 5 and 18 year and over onethird $(36 \%)$ of adolescents ( $40 \%$ of the girls and $32 \%$ of the boys) are anaemic (haemoglobin, $\mathrm{Hb}$, levels $<11 \mathrm{~g} / \mathrm{dL}$ ). The prevalence was markedly higher in some provinces than in others, ranging from $72 \%$ of preadolescents in the NorthWestern Province to $50 \%$ in Uva Province.

Anaemia in these two groups have long-term consequences as the deficiency is likely to persist into adult life. The same survey showed that one in two non-pregnant women and one in three pregnant women, and one in every two infants and pre-schoolers are anaemic. Iron deficiency anaemia during childhood has adverse effects on cognition $(1,2)$.

A recent study by the Medical Research Institute (3) has demonstrated the feasibility of distributing iron supplements through schools, and the efficacy of a weekly dose as against a daily dose of supplements. The study also demonstrated the cost effectiveness of such a programme.

This is a report of a study, undertaken in February and March 1998, to

i. ascertain the response of relevant groups of persons to the possibility of devising programmes for distributing iron supplements through schools to the school-going population, and

ii. to suggest a feasible and practical programme for reducing iron deficiency among schoolage children.

\section{Methods}

The study was carried out in 7 provinces.

It was launched with a meeting held in Colombo at which presentations were made to Provincial Secretaries and Provincial Directors of Education and Health on iron deficiency, its consequences and possible interventions. This was followed by workshops in all the provinces (excluding the North and Eastern Provinces). Each workshop brought together about 30 participants from the province, including health and education secretaries, provincial directors, Medical Officers of Health (MOHs), school principals, community leaders, parents and members of school development societies.

Officials of both health and eduction sectors expressed a commitment to the programme that was discussed, and an initial plan of action was drawn up. A series of action programmes was planned, following progressive awareness raising programmes, going down to zones and finally to the level of the school.

The discussions at these workshops were supplemented with several consultations with subject specialists, officials at decision making levels from the ministries of health and education in the Central Government, and MOHs, in order to formulate a tentative programme which can be implemented in the provinces, with several options and-adequate flexibility.

\section{Results}

\section{A. Provincial plans from workshop reports}

i. Issue of iron supplements to school children

1. Executive Director, Marga Institute, 93/10, Dutugemunu Street, P.0. Box 601, Kirilapone, Colombo 6. 
There was general agreement that iron supplements should be given to school children. They differed on how and who should administer the supplements. Six provinces accepted the plan for once weekly administration at school to ensure compliance, under the supervision of the class teacher. The Southern Province suggested that, in small and medium sized schools, all children be given iron supplements, while in the larger schools only children identified as being iron deficient at a pre-examination be given iron tablets. The Sabaragamuwa Province was the exception, preferring to refer to the $\mathrm{MOH}$ children identified as being iron deficient, and the $\mathrm{MOH}$ to issue tablets to parents for administering to their children.

The school teachers are to maintain records and ensure monitoring. The main concern was the possibility of side effects and how they should be handled, if distribution is done at schools.

\section{ii. Pre-examination}

All provinces recognised the need for a pre-examination prior to administration of supplements, with monitoring every 6 months. Prior deworming and, in malarial areas, treatment for malaria, were advocated.

Most of the provinces suggested clinical assessment by medical officers initially, and periodic monitoring by teachers trained in health science, home science and home economies as well as other teachers. A staggered programme of diagnosis and monitoring, extending throughout the first term of each year, was suggested.

\section{iii. Institutional support}

All provinces worked out detailed institutional structures providing maximum participation by all concerned. Steering and operational committees, from provincial to zonal and divisional levels, were suggested.

\section{iv. Supplies and storage}

Supplies were to be channelled through the MOH. A week's supply was to be obtained by the principal and distributed to the class teacher on the days set apart for iron supplementation.

\section{Awareness raising}

All workshops drew up extensive plans to educate and inform the children, by introducing a health lesson to each class, and then by activities such as debates, poster competitions and health exhibitions. All agreed on the need to use the media to alert parents and the community on the dangers of iron deficiency, and on meeting the problem through changes in the diet as well as through supplementation.

Other suggestions were the promotion of school gardens for fruits and iron rich vegetables, school health clubs, and observing an Anaemia Day in the school calendar.

\section{B. A strategy for a school programme}

\section{Expand and modify the current school medical programme}

At present the $\mathrm{MOH}$ and his staff carry out a worm treatment programme in selected schools, for children in years 1,4 and 7. Constraints such as shortage of public health staff, equipment and trained personnel have circumscribed the programme. However, the techniques, forms and procedures are clearly laid down in a health sector manual (4). One of the major draw backs, in the opinion of health authorities, is the perception of the school medical programme solely as a health programme, resulting in the distancing of education officials from the programme. Even within the health sector it is seen as the concern mainly of the PHI.

The active participation of education officials, school principals and teachers, other health officials such as Assistant and Registered Medical Practitioners, Divisional Medical Officers and parents was suggested.

The programme should be systematically planned. An initial bench mark survey of deficiency diseases, including anaemia should be followed by a monitoring examination at the end of 2 years. 
These examinations could be staggered, from January to March each year.

Some options to be considered are:

i. Provinces muster personnel, techniciansand hospital facilities for the bench mark and monitoring examinations. The economics of using electronic equipment for $\mathrm{Hb}$ levels, be considered.

ii. Initially, limit programme to years $1,4,7$ and include 9 , to cover adolescents.

iii. Modify the prescribed forms and health cards to include anaemia. Device a data and record system for each school, data to be available at provincial level as well.

iv. In schools of type $1 \mathrm{C}, 1 \mathrm{AB}$, obtain consent of parents of iron deficient children to administer supplies. If parents so wish, they could take responsibility of administering supplements, provided they ensure compliance. Regular monitoring of programme will be needed to measure its effectiveness.

Supplements will take the form of a combined tablet containing $200 \mathrm{mg}$ ferrous sulphate and 20 microgram of folic acid and a tablet of $100 \mathrm{mg}$ of vitamin C, as recommended by the MRI, to be taken weekly.

v. Supplementation to be preceded by deworming.

vi. Train selected teachers to make clinical assessment of anaemia. The medical examination will take place only once a year or once in 2 years.

\section{Supplies and Storage}

Supplies to be obtained by $\mathrm{MOH}$ through the usual channels from the national supplies programme, the school principals to obtain a weeks supply from $\mathrm{MOH}$ and class teacher or trained monitor will administer tablets, after lunch or snack. Tablets to be taken in the presence of the teacher.

\section{Cost sharing}

Parents, at least in schools $1 \mathrm{C}$ and $1 \mathrm{AB}$ should be requested to pay for the tablets.

\section{Awareness raising, education and information}

The provinces were ready to commence the programme even in 1998. To begin with, awareness programmes were to be conducted for officials, parents, teachers, community and children on,
a. effects of iron deficiency
b. iron rich foods and enhancing absorption
c. need for supplements
d. possible side effects

A health related lesson to be started in every class. The NIE to introduce a nutrition component into the school curriculum, in grades 1 to 5 in environmental studies and in grades 6 to 9 in health and physical education.

Adapt material from the Health Education Bureau in innovative campaigns.

\section{Numbers and Cost}

Bench mark examination, in years 1, 4, 7 and 9 in each province will involve numbers ranging from 93500 in the NCP to about 295,000 in WP. If the examination is to be conducted between January and March, assuming each technician can examine 50 children per day, number of health personnel needed will range from 30 in Uva to 100 in WP. Accounting only MOHs and PHIs the numbers range from 84 in Uva to 224 in WP. If the services of DMOs, RMPs and AMPs are solicited, there should be no shortage of personnel for the bench mark examination. The monitoring examination will be for iron deficient children only and numbers of children and health personnel will be half the figures quoted above.

The numbers of children and health personnel involved are given in Table 1. Cost of the initial medical examination is assessed in Table 2 and the cost of the $\mathrm{Hb}$ examination in Table 3. Table 4 summarises the cost of the initial survey and one years supplement. 
Table 1

Children in years $1,4,7,9-$ Number of officials required and available

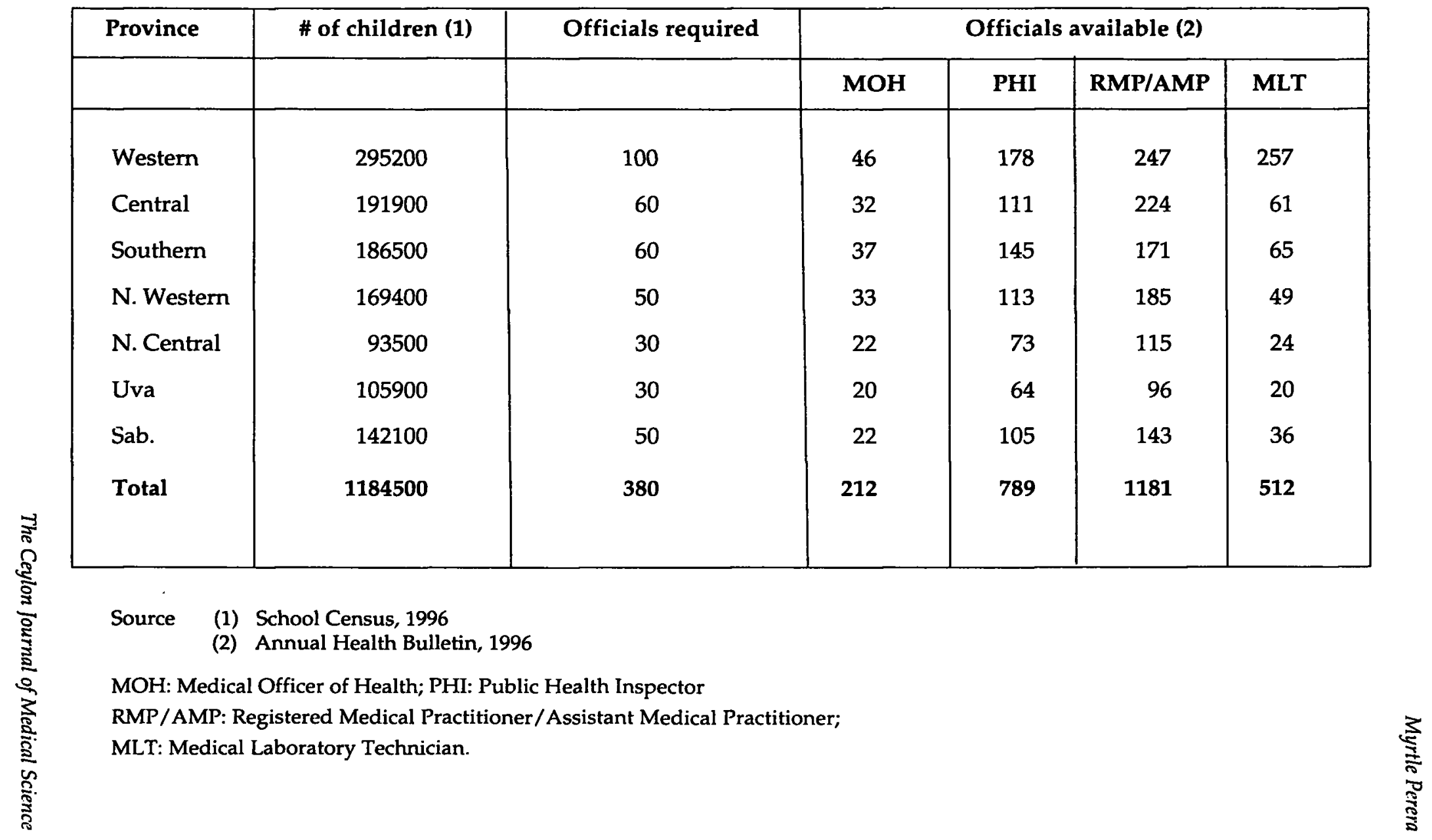




\section{Table 2}

Cost of Initial Medical Examinations

\begin{tabular}{llc}
\hline Province & \multicolumn{1}{c}{ Calculation } & Cost per province \\
\hline Western & Rs. $500^{*} \times 100$ persons $\times 60$ days & Rs. Mln 3.0 \\
Central & Rs. $500 \times 60$ persons $\times 60$ days & Rs. Mln 1.8 \\
Southern & Rs. $500 \times 60$ persons $\times 60$ days & Rs. Mln 1.8 \\
N. Western & Rs. $500 \times 50$ persons $\times 60$ days & Rs. Mln 1.5 \\
N. Central & Rs. $500 \times 30$ persions $\times 60$ days & Rs. Mln 0.9 \\
Uva & Rs. $500 \times 30$ persons $\times 60$ days & Rs. Mln 0.9 \\
Sab. & Rs. $500 \times 50$ persons $\times 60$ days & Rs. Mln 1.5 \\
Total & & Rs. Mln $11.4^{* *}$ \\
\hline
\end{tabular}

* Calculation based on allowance of Rs. 500 for medical officer per day.

* This would amount to approximate Rs. 10 per child.

Rs. Mln = millions of rupees.

Table 3

Cost of Iron Supplements

\begin{tabular}{ll}
\hline Province & $\begin{array}{l}\text { Costs } \\
\text { Rs.(thousands) }\end{array}$ \\
\hline Western & 444 \\
Central & 290 \\
Southern & 280 \\
N. Western & 250 \\
N. Central & 144 \\
Uva & 156 \\
Sab. & 216 \\
Total & 1,730 \\
& (approx. 1.7 million) \\
\hline
\end{tabular}

The maximum cost - according to the MRI study is Rs. 3.24 (inclusive of deworming) per child per week, amounting to Rs. 12.96 per child per month. If one takes Rs. 12.50 per month it will amount to Rs. 150 per year. On the assumption that all children in the years $1,4,7$ and 9 are given iron tablets the approximate cost for one year in given above: 
Table 4

Summary of costs (in millions of rupees)

\begin{tabular}{|l|c|c|c|c|}
\hline \multirow{2}{*}{ Province } & \multicolumn{3}{|c|}{ Cost of Activity } & \multirow{2}{*}{ Total } \\
\cline { 2 - 4 } & 1 & 2 & 3 & \\
\hline \multirow{2}{*}{ Western } & 3.0 & 3.0 & 0.4 & 6.4 \\
Central & 1.8 & 1.9 & 0.3 & 4.0 \\
Southern & 1.8 & 1.8 & 0.3 & 3.9 \\
North Western & 1.5 & 1.6 & 0.2 & 3.3 \\
North Central & 0.9 & 0.9 & 0.1 & 1.9 \\
Uva & 0.9 & 1.0 & 0.2 & 2.1 \\
Sub. & 1.5 & 1.4 & 0.2 & 3.1 \\
Total & 11.4 & $11.6^{*}$ & 1.7 & 24.7 \\
& & & & \\
\hline
\end{tabular}

1 - Bench mark survey (Table 2); 2 - Laboratory tests 3: iron supplements (Table 3)

* Laboratory tests - at Rs. 10/= per test the total would come to Rs. 11.6 Mln

The cost per child for the entire programme is about Rs. 20/-per year. Adding another Rs. 10/to meet the cost of disposable needles and other contingencies, the cost per child will be Rs. 30/per year or Rs. 2.50 per month.

\section{Conclusions}

The desire expressed by the provinces for awareness programme to be started immediately needs to be acted upon with the assistance of the Health Education officers in the provinces.

The commitment of the workshops to formulate and implement a strategy for distributing supplements in the school is encouraging. Full involvement of the parents in the programme should be aimed at and achieved.

There was a clear commitment to combined action by health and education authorities and officials of other sectors as well.
Participation of all relevant persons - parents, community leaders, village physicians, local administrators and planners - was recognised as the key to success.

A well formulated awareness programme will meet issues relating to side effects and compliance as well as recommend changes in dietary patterns such as inclusion of dried fish and sprats with vegetables. In time such information will enter the vast pool of common knowledge and wisdom within communities around the schools.

A rough estimate of the cost of the programme demonstrates its economic feasibility and affordability of successfully minimising the many adverse effects of iron deficiency anaemia. Schools provide the widest coverage in a captive population for addressing a problem which has such critical implications for the social well being, quality of life and for enhancing economic performance. 


\section{Acknowledgements}

The author would like to thank a number of individuals who provided inputs to the study, very specially Drs Chandrani Piyasena and Renuka Jayatissa of the Medical Research Institute, Dr S. Manickarajah of the Ministry of Health, Dr H. M. S. S. D. Herath (former DDG. HPS), Mr. Upasena Senanayaka - Additional Secretary Ministry of Education, Dr. K. C. S. Dalpathado [DDG (Planning) Ministry of Health).

For financial assistance by OMNI (USA). Dr. Penny Nestel who edited the main report.

The Provincial Directors of Education and Health including their staff in the seven provinces in which the workshops were conducted, Prof. T.W. Wikramanayake for editing the manuscript, and finally the team of consultants, research assistants and field investigators.

The external consultants were Mr. P. P. M. Gunatilleke, Mr. K. S. Perera and Mr. Sunil Fernando.

The members of the Marga Team were Mr. D. H.
Sathischandra, Mr. Upali Peiris, Mr. Priyantha Gamini and Ms. Chulani Kulatunga.

\section{References}

1. Pollitt E. Effects of a diet deficient in iron on the growth and development of preschool and school-age children. Food and Nutrition Bulletin 1991; 13: 110-118

2. Grantham-McGregor SM, Fernald LC, Sethuvarman K-Effects of health and nutrition on cognition and behavioural development in children in the first three years of life. Infections and micronutrient deficiencies: iodine, iron, and zinc.Food \& Nutrition Bulletin 1991; 20: 76-94

3. Ministry of Health and Indigenous Medicine, Department of Nutrition, Medical Research Institute in collaboration with the World Health Organization: Daily vs. weekly iron supplementation effects on adolescent school girls 1997/98.

4. Herath HMSSD. ed. A manual for Public Health Inspectors, Ministry of Health, 1989. 